\title{
ANÁLISE DA RETENÇÃO DE ANTOCIANINA EM BETERRABAS DESIDRATADAS ATRAVÉS DE MÉTODOS COMBINADOS DE SECAGEM
}

\author{
C. C. MACAGNAN ${ }^{2}$, F. W. RIGHES ${ }^{2}$, L. M. TERRA ${ }^{1}$,R. SALVALAGGIO ${ }^{2}$ e S. \\ SCHMALTZ2. \\ ${ }^{1}$ Universidade Federal de Santa Maria, Departamento de Engenharia Química \\ ${ }^{2}$ UniversidadeFederal de Santa Maria, Faculdade de Engenharia Química \\ E-mail para contato: resalvalaggio@gmail.com
}

\begin{abstract}
RESUMO - A beterraba é um alimento que apresenta cultura compatível com climas variados, com funcionalidade conferida pela antocianina, buscou-se assim, determinar a combinação tempo e temperatura em que a beterraba conservasse mais a antocianina, através de condições predeterminadas de secagem em túnel de vento e estufa, obtendo-se uma maior conservação em túnel de vento (retenção de $92,90 \%$.).
\end{abstract}

\section{INTRODUÇÃO}

Produtos de origem vegetal apresentam, em geral, reduzidos tempos de armazenamento, principalmente, pelo alto teor de água. A água é um componente inerente aos alimentos e, ao mesmo tempo, contribui para acelerar o seu processo de deterioração. A eliminação da umidade por processos de secagem permite a redução de peso e, geralmente, também é acompanhada por diminuição de volume, fato que incide na redução dos custos de transporte, embalagem e armazenamento de produtos desidratados, sendo estes fatores de estímulo para a sua produção e sua comercialização (Fellows, 1994).

Considerando que a produção de beterraba no Brasil é uma das mais significativas dentro do volume total do mercado agrícola de hortaliças e que a beterraba (Beta vulgaris) é uma hortaliça que possui uma cultura compatível com diversos tipos de clima, mas o temperado é o mais indicado para seu cultivo, visamos a obtenção de um produto que mantivesse seu valor nutricional e apresentasse maior durabilidade, desenvolvendo experimentos através da secagem da beterraba.

Esta hortaliça apresenta características de alimento funcional, como a antocianina e, assim, apresenta-se como um alimento nutricionalmente muito atraente. São considerados alimentos funcionais aqueles que, além de fornecerem a nutrição básica, promovem a saúde, devendo ser salientado que esse efeito restringe-se à promoção da saúde e não à cura de doenças.

O termo antocianina vem do grego (anthos, uma flor, e kyanos, azul escuro). Segundo Harborne e Grayer (1988), após a clorofila, as antocianinas são o grupo mais importante de pigmentos de origem vegetal. Esses pigmentos conferem diferentes tonalidades de cor, 


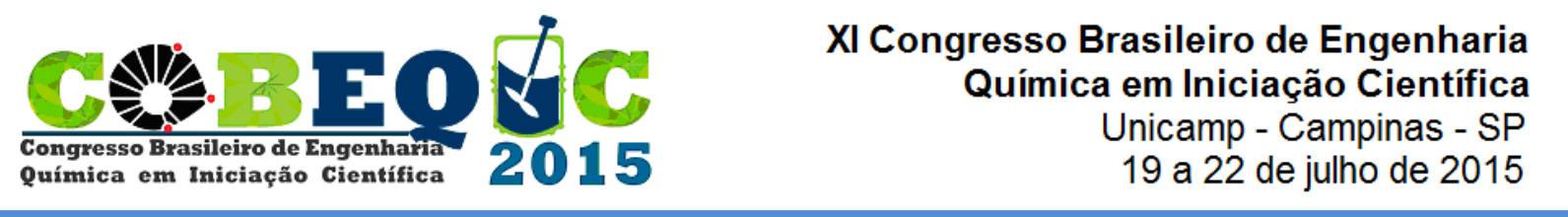

oscilando entre vermelho, laranja e roxo, de acordo com condições intrínsecas, como o pH, encontradas nos vegetais (Brouillard,1983).

A provável redução no teor deste composto pode ser explicada por alguns fatores relacionados a sua instabilidade, tal como pelas sucessivas etapas de pré-processamento para a obtenção das beterrabas desidratadas, dentre elas a secagem, trituração, contato com a luz oxigênio entre outros (Bobbio; Bobbio, 2003).

A temperatura é um fator determinante na estabilidade das antocianinas, pois, à medida que uma solução de antocianinas é submetida a uma temperatura superior à ambiente $\left(25^{\circ} \mathrm{C}\right)$, sua degradação é maior, conforme Stringheta (1991).É importante ressaltar que a secagem altera as características do alimento, os pigmentos, por exemplo, sofrem modificações químicas por causa do calor, quanto mais altas as temperaturas maiores as perdas desses pigmentos.

O desenvolvimento de um produto crocante, nutritivo e saboroso, desenvolvido a partir da beterraba, encontra um segmento de destaque no mercado. Assim o presente projeto tem como objetivo determinar a combinação temperatura e tempo de secagem na qual a beterraba apresenta maior conservação de antocianina, buscando-se obter um produto alimentício com baixa atividade de água, que mantenha suas propriedades funcionais e um bom aspecto organoléptico.

\section{MATERIAIS E MÉTODOS}

\subsection{Matéria-prima:}

As beterrabas utilizadas para a técnica foram adquiridas no comércio de Santa Maria, assim como os demais materiais, como o sal e a sacarose comercial, utilizados no banho osmótico.

\subsection{Procedimento experimental:}

O método consistiu em realizar secagens em amostras triplicatas de beterrabas previamente tratadas em banho osmótico por $2 \mathrm{~h}$ a $40^{\circ} \mathrm{C}$. As condições ótimas de secagem, do ponto de vista organoléptico, foram selecionadas em estudo anterior, tanto em secador túnel de vento como em estufa e suas características são apresentadas a seguir.

$\checkmark$ Túnel de vento; temperatura $51,1{ }^{\circ} \mathrm{C}$; tempo de 3 horas e 42 minutos; velocidade $1,0 \mathrm{~m} . \mathrm{s}-1$.

$\checkmark$ Túnel de vento; temperatura $68,9{ }^{\circ} \mathrm{C}$; tempo de 3 horas e 42 minutos; velocidade 2,0 m.s- 1 .

$\checkmark$ Túnel de vento; temperatura $75^{\circ} \mathrm{C}$; tempo de 3 horas e 15 minutos; velocidade $1,55 \mathrm{~m} . \mathrm{s}-1$.

$\checkmark$ Estufa; temperatura $55^{\circ} \mathrm{C}$; tempo de 5 horas. 


\section{$\checkmark$ Estufa; temperatura $65,6^{\circ} \mathrm{C}$; tempo de 4 horas e 24 minutos. \\ $\checkmark$ Estufa; temperatura $70^{\circ} \mathrm{C}$; tempo de 3 horas.}

A primeira etapa do procedimento consistiu em, após o descascamento, as beterrabas serem cortadas em rodelas e pesadas, a fim de constituírem as amostras. Estas, foram colocadas em banho osmótico a $40^{\circ} \mathrm{C}$ por $2 \mathrm{~h}$, contendo $1,83 \%$ sal, $48,5 \%$ açúcar e $49,67 \%$ de água. Após o tratamento osmótico as amostras foram submetidas às diferentes condições de secagens nos equipamentos citados anteriormente. Na sequência, as amostras eram novamente pesadas e então submetidas ao método de quantificação da antocianina retida no produto.

\subsection{Quantificação do teor de antocianina:}

A funcionalidade do produto obtido em cada ensaio foi testada a partir da quantidade de antocianina que permaneceu na beterraba depois do tratamento osmótico e da secagem. Para a realização desta determinação, foi necessário realizar um tratamento na amostra seca, e se empregou o método pH único, conforme Teixeira et al. (2008).As etapas são discriminadas abaixo:

$\checkmark$ Trituração e pesagem da amostra seca;

$\checkmark$ Adição de solução extratora de etanol-água (70/30) com pH 2 à amostra, deixando-a na geladeira por $24 \mathrm{~h}$ e a $5^{\circ} \mathrm{Cao}$ abrigo de luz, a fim de extrair a antocianina do produto a ser analisado;

$\checkmark$ Filtração simples coletando o filtrado em balão de $100 \mathrm{ml}$, o qual teve seu volume completado com a solução extratora;

$\checkmark$ Centrifugação a 2000rpm por 10 minutos, seguida de nova filtração simples;

$\checkmark$ Extração da clorofila presente na amostra com o solvente éter de petróleo;

$\checkmark$ Análise da amostra através do método do $\mathrm{pH}$ único:

a. Coleta-se uma alíquota de $10 \mathrm{~mL}$ e adicionada em balão volumétrico de $50 \mathrm{~mL}$ completando-se o volume com solução etanol/HCl (85:15), solução padrão;

b. Mede-se a absorbância em espectrofotômetro, com o comprimento de onda de $535 \mathrm{~nm}$.

A partir de análises realizadas em laboratório determinou-se o teor de antocianinas nas amostras por meio da Equação 1. 
$A n t T t_{m g A n t / 100 g}=\frac{D O^{*}{ }_{535 \mathrm{~nm}} \cdot V_{E 1} \cdot V_{E 2} \cdot 1000}{V_{A l q} \cdot m \cdot E_{1 \mathrm{~cm}}^{1 \%}}$

(1)

\section{RESULTADOS E DISCUSSÃO} 1.

Os resultados encontrados podem ser expressos pela Tabela 1, assim como pela Figura

Figura 1 - Teor de antocianinas para diferentes processos.

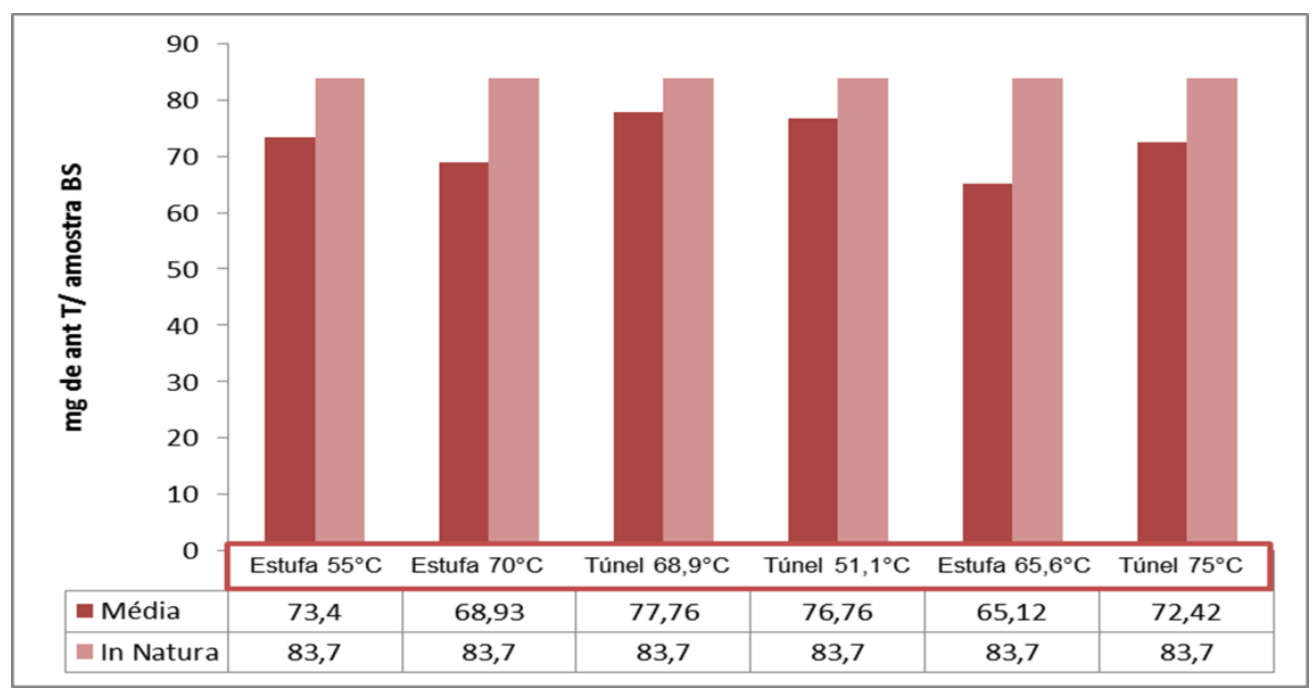

Tabela 1- Análises laboratoriais.

\begin{tabular}{|c|c|c|c|c|c|c|}
\hline Tempo & Equipamento & Amostra 1 & Amostra 2 & Média & $\begin{array}{l}\text { In Natura } \\
\text { (mg de } \\
\text { ant/100g de } \\
\text { amostra } \\
\text { seca) }\end{array}$ & $\begin{array}{l}\text { Porcetagem de } \\
\text { Retenção }\end{array}$ \\
\hline $3 \mathrm{~h} 42 \mathrm{~min}$ & Túnel $\left(68,9^{\circ} \mathrm{C} 2 \mathrm{~m} / \mathrm{s}\right)$ & 77,76 & 77,76 & 77,76 & 83,7 & 92,90 \\
\hline $3 \mathrm{~h}$ & Estufa $\left(70^{\circ} \mathrm{C}\right)$ & 59,15 & 78,51 & 68,93 & 83,7 & 82,35 \\
\hline $5 \mathrm{~h}$ & $\operatorname{Estufa}\left(55^{\circ} \mathrm{C}\right)$ & 85,54 & 61,26 & 73,40 & 83,7 & 87,69 \\
\hline $4 \mathrm{~h} 24 \mathrm{~min}$ & $\operatorname{Estufa}\left(65,6^{\circ} \mathrm{C}\right)$ & 79,36 & 50,89 & 65,12 & 83,7 & 77,80 \\
\hline $3 \mathrm{~h} 43 \mathrm{~min}$ & Túnel $\left(51,1^{\circ} \mathrm{C} 1 \mathrm{~m} / \mathrm{s}\right)$ & 76,76 & 76,76 & 76,76 & 83,7 & 91,70 \\
\hline $3 \mathrm{~h} 15 \mathrm{~min}$ & Túnel $\left(75^{\circ} \mathrm{C} 1,55 \mathrm{~m} / \mathrm{s}\right)$ & 93,83 & 51,02 & 72,42 & 83,7 & 86,52 \\
\hline
\end{tabular}


Observaram-se melhores resultados para as secagens feitas em túnel de vento, a temperaturas mais altas e tempos intermediários. Em todos os resultados obtidos foi possível notar que o emprego da estufa implicou em uma degradação da antocianina maior que o do túnel de vento. Percebeu-se, ainda, que bons resultados também são obtidos a temperaturas menores e tempos maiores de secagem.

O equipamento túnel de vento com a temperatura de $68,9^{\circ} \mathrm{C}$ a uma velocidade de $2 \mathrm{~m} / \mathrm{s}$ durante $3 \mathrm{~h}$ e $42 \mathrm{~min}$, é o mais indicado para o processo de secagem visto que a degradação do teor de antocianina é menor.

Salientamos que os dados foram analisados apenas quanto ao teor de antocianina conservado, não levando em consideração o gasto energético resultante entre os diferentes tempos de secagem.

\section{NOMENCLATURA}

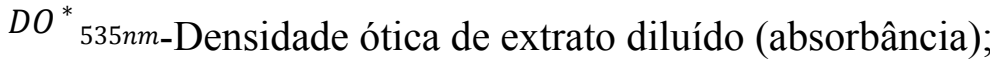

$E_{1 c m-\text { Coeficiente de extinsão. }}^{1 \%}$

m- massa da amostra $(\mathrm{g})$;

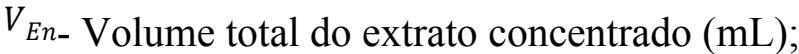

$V_{\text {Alq- }}$ Volume da alíquota do extrato primário a ser diluída para fazer o extrato secundário $(\mathrm{mL})$;

\section{CONCLUSÃO}

A secagem da beterraba em túnel de vento apresentou melhores resultados, a $68,9^{\circ} \mathrm{C}$, com duração de $3 \mathrm{~h}$ e $42 \mathrm{~min}$ e velocidade do ar de $2,0 \mathrm{~m} \cdot \mathrm{s}^{-1}$, com $92,90 \%$ de retenção. Como foi possível observar, a secagem em túnel de vento resultou em menor degradação da antocianina, e ainda, melhores resultados são obtidos a temperaturas menores e tempos maiores de secagem.

\section{REFERENCIAS}

BOBBIO, F. O.; BOBBIO, P. A. Introdução à química de alimentos. 3 ed. São Paulo: Varela, 2003. 238 p.

BROUILLARD, R., The in vivo expression of anthocyanincolour in plants,Phytochemistry, v.22, p.1311-1323, 1983

FELLOWS, P. Tecnologia del processado de losalimentos: princípios y prácticas. Traducidopor F. J. S.Trepat. Zaragoza: Acribis, 1994.

HARBORNE, J.B.; GRAYER, R.J., The anthocyanins.In:Theflavonoids: advancesin research since 1980.Chapmam \& Hall, London, 1988, p. 1-20. 
STRINGHETA, P.C.; Identificação da estrutura e estudo da estabilidade das antocianinas extraídas da inflorescência de capim gordura (Mellinisminutuflora, Pal de Beauv.), Campinas, 1991,138 p. Tese (Doutorado em Ciência e Tecnologia de Alimentos) UNICAMP.

TEIXEIRA, L; STRINGHETA, P.C.; OLIVEIRA, F.A.de. Comparação de métodos para quantificação de antocianinas. Revista Ceres, p. 297- 304, 2008. 